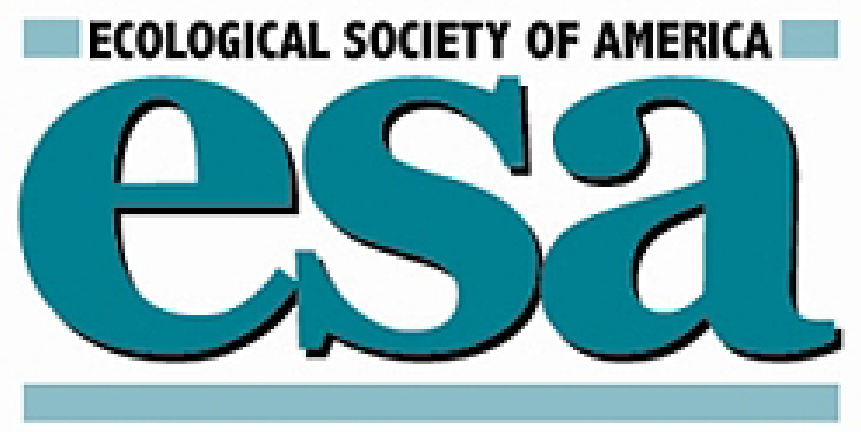

Accuracy of Visible and Ultraviolet Light for Estimating Live Root Proportions with Minirhizotrons

Author(s): Zhengquan Wang, Walter H. Burch, Pu Mou, Robert H. Jones and Robert J. Mitchell

Source: Ecology, Vol. 76, No. 7 (Oct., 1995), pp. 2330-2334

Published by: Ecological Society of America

Stable URL: http://www.jstor.org/stable/1941705

Accessed: $12 / 03 / 201414: 26$

Your use of the JSTOR archive indicates your acceptance of the Terms \& Conditions of Use, available at http://www.jstor.org/page/info/about/policies/terms.jsp

JSTOR is a not-for-profit service that helps scholars, researchers, and students discover, use, and build upon a wide range of content in a trusted digital archive. We use information technology and tools to increase productivity and facilitate new forms of scholarship. For more information about JSTOR, please contact support@jstor.org. 
Ecology, 76(7), 1995, pp. 2330-2334

(C) 1995 by the Ecological Society of America

\section{ACCURACY OF VISIBLE AND ULTRAVIOLET LIGHT FOR ESTIMATING LIVE ROOT PROPORTIONS WITH MINIRHIZOTRONS}

\author{
Zhengquan Wang, ${ }^{1}$ Walter H. Burch, ${ }^{2} \mathrm{Pu} \mathrm{Mou},{ }^{3}$ \\ Robert H. Jones, ${ }^{4}$ and Robert J. Mitchell ${ }^{5}$
}

The minirhizotron technique has been widely used to study roots in both natural and managed ecosystems (Box and Hammond 1990, Atkinson 1991, Murphy et al. 1994). Parameters estimated include root depth (Gregory 1979, Upchurch and Ritchie 1983, Parker et al. 1991, Hendrick and Pregitzer 1992a), root length density (Upchurch 1985, 1987, Bland and Dugas 1988, Box and Ramseur 1993, Volkmar 1993, Samson and Sinclair 1994), root morphology (Upchurch 1985, Hendrick and Pregitzer 1992b), root dynamics (Hansson and Andrén 1987, Eissenstat and Caldwell 1988), and root turnover (Cheng et al. 1990, 1991, Hendrick and Pregitzer 1992b). For estimates of dynamics or turnover, the reliability of the minirhizotron method depends on the accuracy of assessing physiological status of roots, i.e., whether roots are live or dead.

Root color is the most frequently used criterion for determining physiological status of roots in minirhizotrons (Cheng et al. 1990, Hendrick and Pregitzer $1992 a, b)$. When roots become dark brown or black, they are counted as dead. However, root color may darken as a result of secondary growth or suberization, and this can complicate visible estimates of physiological status. Furthermore, under visible light, it is sometimes difficult to distinguish between roots and organic debris.

To aid in separation of live and dead roots, some of the more recently manufactured minirhizotron systems

\footnotetext{
'Department of Forest Science, Northeast Forestry University, Harbin, 150040, People's Republic of China.

${ }^{2}$ Coweeta Hydrologic Laboratory, 3160 Coweeta Lab Road, Otto, North Carolina 28763 USA.

${ }^{3}$ Department of Forestry, Virginia Polytechnic Institute and State University, Blacksburg, Virginia 24061-0324 USA

${ }^{4}$ Department of Biology, Virginia Polytechnic Institute and State University, Blacksburg, Virginia 24061-0406 USA. Send reprint requests to this author.

5 J. W. Jones Ecological Research Center, Route 2, Box 2324, Newton, Georgia 31770 USA.
}

include both visible and ultraviolet (UV) lights. Under UV light, live roots fluoresce more strongly than dead roots. However, no published information is available on the precision or accuracy of measuring live roots with either visible or UV light. Without this information, accuracy of estimating root turnover is unknown. Therefore, this study was designed with the following objectives: (1) to determine the accuracy of estimating the live proportion of fine roots using visible and ultraviolet light sources in a minirhizotron camera system; and (2) to determine if estimates are consistent among different species and growth forms. Estimates from visible and UV light were compared with those from a root stain-dissection technique for eight plant species common to early successional upland forests in the southeastern United States.

\section{Methods}

The eight plant species were chosen to reflect a broad spectrum of growth forms (Table 1). Root samples of Pinus taeda L. and Liquidambar styraciflua L. were collected from seedlings grown outdoors in a sand box at the Auburn University campus in east-central Alabama. For the rest of the species, roots were collected from a clearcut forest adjacent to an existing minirhizotron study at the Auburn campus (Burch 1995). All root samples were excavated between 20 September and 15 October 1993, 2 yr after the forest was harvested.

The root samples were moistened, immediately sealed in polyethylene bags, and stored in a cooler filled with cold water for no more than $2 \mathrm{~h}$. In the laboratory, roots were washed several times with tap water and then distilled water. All fine roots $(<2 \mathrm{~mm}$ in diameter, a criterion used in many fine-root studies) were clipped off and cut into $2 \mathrm{~cm}$ long segments. Subsamples were then randomly selected to produce 30 replicates of 30 root segments each (900 root segments for each species). The division of the 900 segments into 30 samples of 30 subsamples was an a priori attempt to optimize the power of statistical tests (increased by more samples) vs. the precision of estimating percent living roots (increased by more subsamples).

A minirhizotron observation apparatus was constructed in the laboratory. A $5.1 \mathrm{~cm}$ diameter extruded acrylic observation tube (about a $20 \%$ UV reduction, Bartz Technology, Santa Barbara, California, personal communication) similar to those commonly used in field studies was clamped to a table. The tube was completely wrapped with black paper and dark tape except for a $20 \times 3 \mathrm{~cm}$ observation window. All 30 root segments of each root sample were arranged without overlap along the observation window and covered 
TABLE 1. Species tested, life form, mean proportion of live roots estimated by three methods, and mean differences between light and TTC (2,3,5-triphenyltetrazolium chloride) estimates of live root proportion; standard deviations are shown in parentheses.*

\begin{tabular}{|c|c|c|c|c|c|c|}
\hline \multirow[b]{2}{*}{ Species } & \multirow[b]{2}{*}{ Life form } & \multicolumn{3}{|c|}{ Prop. live roots estimated by } & \multicolumn{2}{|c|}{$\begin{array}{l}\text { Light method estimate } \\
\text { minus TTC estimate }\end{array}$} \\
\hline & & Visible light & UV light & TTC & Visible & UV \\
\hline Agrostis borealis $\mathrm{H}$. & perennial grass & $\begin{array}{l}0.847+ \\
(0.068)\end{array}$ & $\begin{array}{l}0.941+ \\
(0.038)\end{array}$ & $\begin{array}{c}0.795 \\
(0.042)\end{array}$ & $\begin{array}{r}0.052 \\
(0.075)\end{array}$ & $\begin{array}{r}0.145 \\
(0.048)\end{array}$ \\
\hline Paspalum dilatatum $\mathrm{L}$. & perennial grass & $\begin{array}{l}0.787+ \\
(0.058)\end{array}$ & $\begin{array}{l}0.867+ \\
(0.072)\end{array}$ & $\begin{array}{c}0.695 \\
(0.120)\end{array}$ & $\begin{array}{r}0.092 \\
(0.113)\end{array}$ & $\begin{array}{r}0.172 \\
(0.103)\end{array}$ \\
\hline Solidago spp. & perennial forb & $\begin{array}{l}0.841+ \\
(0.081)\end{array}$ & $\begin{array}{l}0.850+ \\
(0.074)\end{array}$ & $\begin{array}{c}0.758 \\
(0.074)\end{array}$ & $\begin{array}{r}0.083 \\
(0.081)\end{array}$ & $\begin{array}{r}0.092 \\
(0.070)\end{array}$ \\
\hline Erigeron canadensis L. & annual forb & $\begin{array}{l}0.830- \\
(0.098)\end{array}$ & $\begin{array}{l}0.910 \\
(0.069)\end{array}$ & $\begin{array}{c}0.890 \\
(0.073)\end{array}$ & $\begin{array}{l}-0.060 \\
(0.063)\end{array}$ & $\begin{array}{r}0.020 \\
(0.058)\end{array}$ \\
\hline $\begin{array}{l}\text { Rubus } \\
\quad \text { cuneifolius Pursh }\end{array}$ & semiwoody forb & $\begin{array}{l}0.801- \\
(0.068)\end{array}$ & $\begin{array}{l}0.842- \\
(0.063)\end{array}$ & $\begin{array}{c}0.895 \\
(0.049)\end{array}$ & $\begin{array}{l}-0.094 \\
(0.078)\end{array}$ & $\begin{array}{l}-0.052 \\
(0.072)\end{array}$ \\
\hline $\begin{array}{l}\text { Liquidambar } \\
\text { styraciflua } \mathrm{L} .\end{array}$ & deciduous woody & $\begin{array}{l}0.744- \\
(0.115)\end{array}$ & $\begin{array}{l}0.827 \\
(0.105)\end{array}$ & $\begin{array}{c}0.859 \\
(0.139)\end{array}$ & $\begin{array}{l}-0.115 \\
(0.084)\end{array}$ & $\begin{array}{l}-0.032 \\
(0.071)\end{array}$ \\
\hline Quercus nigra L. & deciduous woody & $\begin{array}{l}0.746- \\
(0.076)\end{array}$ & $\begin{array}{l}0.874 \\
(0.065)\end{array}$ & $\begin{array}{c}0.904 \\
(0.052)\end{array}$ & $\begin{array}{l}-0.158 \\
(0.080)\end{array}$ & $\begin{array}{l}-0.030 \\
(0.072)\end{array}$ \\
\hline Pinus taeda $\mathrm{L}$. & evergreen woody & $\begin{array}{l}0.656- \\
(0.093)\end{array}$ & $\begin{array}{l}0.835- \\
(0.058)\end{array}$ & $\begin{array}{c}0.941 \\
(0.055)\end{array}$ & $\begin{array}{l}-0.285 \\
(0.076)\end{array}$ & $\begin{array}{l}-0.106 \\
(0.064)\end{array}$ \\
\hline
\end{tabular}

* Within species, light method means followed by - or + significantly underestimate or overestimate, respectively, the TTC mean $(P<0.05)$ according to ANOVA contrasts, each with 1,87 degrees of freedom.

with dark paper. A minirhizotron camera system (Bartz Technology, Santa Barbara, California) with both visible and ultraviolet lights was used to classify the root segments as either live or dead. For each sample, visible light was always the first method used, UV light was second and staining was last. UV light was second because results from visible light have little or no chance of biasing UV assessment, whereas the reverse may not be true. Staining had to be last because it changes root color.

The following characteristics were used to classify roots as dead under visible light: dark brown, very dark brown, or black in color; partial decay of the existing root; or the appearance and growth of fungal mycelia (nonmycorrhizal) around the root (Hendrick and Pregitzer $1992 a, b$ ). Under ultraviolet light (without visible light) roots with strong fluorescence were counted as live while roots with little or no fluorescence were classified as dead.

Immediately after minirhizotron observations were made, all root segments in a sample were bulked and then immersed in a $0.5 \%$ aqueous solution of $2,3,5$ triphenyltetrazolium chloride (TTC) and incubated in the dark for $24 \mathrm{~h}$. The TTC solution was then poured off, samples were rinsed with cold tap water for 3-4 $\mathrm{s}$, and roots were examined under a stereo dissecting microscope $(7-30 \times)$. Pink or red roots were counted as live, while colorless roots were tallied as dead. Tetrazolium is biologically reduced (mostly by dehydrogenase) in living tissue from its original colorless state to the water-insoluble red compound formazan. In sev- eral studies, TTC has been successfully used to separate live from dead roots (Jacques and Schwass 1956, Knievel 1973, Joslin and Henderson 1984, Clemensson-Lindell 1994). We dissected many roots of each species to ensure that there was adequate penetration by the dye. Even without the dissection, differences between live and dead roots were obvious. We considered TTC results as the standard against which the results from visible and UV light observations were compared.

The proportions of live roots were calculated for each sample of 30 root segments using each method (i.e., visible light, ultraviolet light, and TTC stain). Accuracy of each light method was then assessed by two equations:

$$
\begin{aligned}
& A=L-\mathrm{TTC}, \\
& A=1-(|L-\mathrm{TTC}| / \mathrm{TTC}),
\end{aligned}
$$

where $A$ is accuracy, $L$ is proportion of live roots using visible or UV light, and TTC is the same proportion using the TTC method. Eq. 1 assesses the direction of inaccuracy, which is the tendency to under- or overestimate true live root proportion. Eq. 2 is a directionless estimate of the magnitude of inaccuracy relative to the TTC standard. The value of Eq. 2 changes if dead root proportion is used instead of live root proportion.

Using data from Eq. 1, we employed a nested ANOVA (replicates nested within species) to determine if the two light methods had the same accuracy across all species. ANOVAs with single degree of freedom con- 
trasts were used within each species to examine where each method under- or overestimated the TTC standard. Orthogonal contrasts within light methods were used to determine if live root proportion estimates were different for woody vs. nonwoody growth forms.

\section{Results}

Visible light underestimated percent live roots (overall mean $=0.782$ ), while UV light overestimated (mean $=0.868$ ) when compared to the TTC standard (mean $=0.846)$. Analysis of Eq. 1 detected a significant light method effect $(F=418.0 ; \mathrm{df}=1,232 ; P<0.0001)$. However, a significant method $\times$ species interaction also occurred $(F=18.3 ; \mathrm{df}=7,232 ; P<0.0001)$, an indication that accuracy of light methods changed from one species to another. When analyzed within species, visible light significantly underestimated live root proportion in five species and overestimated in three (Table 1). Ultraviolet light significantly underestimated in two species, overestimated in three, and provided statistically similar results in three species.

There was a tendency for both light methods to overestimate accuracy in nonwoody species and to underestimate in woody species (Table 1). Within each light method, orthogonal contrasts between the woody and nonwoody species were significant $(F \geq 310.0$; df $=$ 1, 232; $P<0.0001)$. Visible light appeared most accurate for the two grass species, both methods had similar accuracy in Solidago spp., and ultraviolet light was more accurate in all others (Table 1).

Differences between estimates made by either light method and the TTC standard were small when considered as a proportion of the TTC mean. Based on Eq. 2 , mean accuracy of all species combined was 0.847 for visible light and 0.877 for UV light. According to $t$ tests, both of the latter were significantly different from a perfect accuracy of $1.000(t=20.1$ for visible and 16.9 for UV light; $P<0.0001)$. When species were considered separately, the range in accuracy for visible light was 0.697 (P. taeda) to 0.924 (E. canadensis), and the range for UV light was 0.715 ( $P$. dilatatum $)$ to 0.947 (E. canadensis).

\section{Discussion and Conclusions}

When data for all eight species were combined, both visible and UV light estimated live root proportions with similar accuracy $(0.847$ for visible and 0.877 for UV). These results imply that either method will produce relatively good estimates for mixed-species communities. In a field setting, however, the visible light method may be easier to use and less costly. When UV light is used, dead roots are hard to see against a soil background; thus, visible light is needed to count dead (or total) roots regardless of method used. If only visible light is used, less time is needed to count roots, and the expense of adding a UV light source to the camera can be avoided.

When species or growth forms were analyzed separately, accuracy of each light method was more variable. Neither method was superior across all species. Results of this study suggest that visible light should be chosen for maximum accuracy in grass-dominated communities and UV light for communities dominated by broad-leaved herbs or woody plants (Table 1).

To achieve and possibly improve on the accuracies observed in this study, one must become familiar with factors that influence visual characteristics of roots (e.g., color and turgor) under both visible and UV light. As seen in the present study, root appearance can vary by growth form (i.e., nonwoody vs. woody) and species. Seasonal variation is also important (Fogel 1985, Hansson and Andrén 1987). Reliability may be improved also if individual roots are observed over time. For example, a dark-colored root initially classified as dead can be viewed later and reclassified as alive if secondary thickening or bark development is observed. Repeated observations of the same root is one of the major advantages of minirhizotrons.

Influences of growth form on root color may explain why estimates of live root proportion under visible light were more accurate for nonwoody than for woody plants (Table 1). Some live roots in woody species were dark in color due to secondary growth or suberization, and under visible light these roots may have been misidentified as dead. In a field situation, this should be a minor problem since the vast majority of fine roots never develop significant secondary thickening.

Under UV light, some dead roots apparently still fluoresced and thus were misidentified as living. The latter problem may be more prevalent in nonwoody species, which would explain why UV light was more accurate among woody species (Table 1).

An additional problem in using ultraviolet light in minirhizotrons is that the intensity of fluorescence is related to protoplasm concentrations, which are highly variable in root cells (Gregory et al. 1987). It is sometimes difficult to distinguish between roots with very little fluorescence (i.e., living roots) and those with none (i.e., dead). A related problem is the contrasting properties of root fluorescence in a single minirhizotron frame. If one root glows much brighter than another, the bright one may be counted as living and the other as dead by contrast alone. However, if the dimmer root is seen without a contrasting brighter root, the dim root may be counted as live. Furthermore, the amount of fluorescence and contrast may be affected by the type of tube used. The acrylic tube used in this study reduces UV light penetration. Tubes made out of CAB (cellulose acetate butyrate) or other materials may be more or less transparent to UV light or fluorescence. One 
possible solution to these problems is to use visible light to check roots after UV light has been used.

Another difficulty is the occurrence of partially live roots. For root length measures, this problem may be especially acute. For root counting methods (i.e., where a root intersects a grid line), we suggest that the root be classified as living if most ( $>50 \%$ of total length) of the root is alive.

An important consideration in root studies is the sample size needed to meet a specified level of precision. To calculate the number of samples (each containing 30 segments) needed for estimates of live root proportion within various percentages of the true mean, we used Stein's two stage sample procedure (Steel and Torrie 1960) with an $\alpha=0.05$ and estimates of the mean and variance from our data (all species combined). To be within $10 \%$ of the mean, seven and four samples would be needed for visible and ultraviolet light, respectively. To be within $5 \%, \approx 27$ and 13 samples would be required, respectively. Even if such sample sizes were met, however, the maximum accuracy of visible and UV light for mixed-species communities (i.e., as defined by Eq. 2) would be somewhere between 0.8 and 0.9 for the ecosystem that we studied. Furthermore, because visibility may be more difficult in the field than in our laboratory study, larger sample sizes (or $>30$ segments per sample) may be needed to reach the same levels of precision and accuracy.

Acknowledgments: The authors thank Mary Miller, Ken McNabb and anonymous reviewers for help with this manuscript; Greg Somers, Sunil Nepal, Harold Burkhart, and an anonymous reviewer for assistance in statistical analysis; and Russell Parrish and Deborah Greco for field and lab assistance. Funding was provided by the Alabama Water Resources Research Institute and by the Alabama Agricultural Experiment Station (AAES). This paper is AAES contribution number 9-944817.

\section{Literature Cited}

Atkinson, D. 1991. Plant root growth: an ecological perspective. British Ecological Society, Special Publication Number 10

Bland, W. L., and W. A. Dugas. 1988. Root length density from minirhizotron observations. Agronomy Journal $\mathbf{8 0}$ : $271-275$.

Box, J. E., Jr., and L. C. Hammond. 1990. Rhizosphere dynamics. Westview Press, Boulder, Colorado, USA.

Box, J. E., Jr., and E. L. Ramseur. 1993. Minirhizotron wheat root data: comparisons to soil core root data. Agronomy Journal 85: 1058-1060.

Burch, W. H. 1995. Rooting habits of loblolly pine, hardwoods, and herbaceous plants during forest regeneration: a minirhizotron study. Thesis. Auburn University, Auburn, Alabama, USA.

Cheng, W., D. C. Coleman, and J. E. Box, Jr. 1990. Root dynamics, production and distribution in agroecosystems on the Georgia Piedmont using minirhizotrons. Journal of Applied Ecology 27:592-604.

Cheng, W., D. C. Coleman, and J. E. Box, Jr. 1991. Measuring root turnover using the minirhizotron technique. Agriculture, Ecosystems and Environment 34:261-267.

Clemensson-Lindell, A. 1994. Triphenyltetrazolium chloride as an indicator of fine-root vitality and environmental stress in coniferous forest stands: application and limitations. Plant and Soil 159:297-300.

Eissenstat, D. M., and M. M. Caldwell. 1988. Seasonal timing of root growth in favorable microsites. Ecology 69: 870-873.

Fogel, R. 1985. Roots as primary producers in below-ground ecosystems. Pages 23-35 in A. H. Fitter, D. Atkinson, D. J. Read, and M. B. Usher, editors. Ecological interactions in soil. British Ecological Society, Special Publication Number 4.

Gregory, P. J. 1979. A periscope method for observing root growth and distribution in field soil. Journal of Experimental Botany 30:205-214.

Gregory, P. J., J. V. Lake, and D. A. Rose. 1987. Root development and function. Cambridge University Press, Cambridge, UK.

Hansson, A. C., and O. Andrén. 1987. Root dynamics in barley, lucerne and meadow fescue investigated with a mini-rhizotron technique. Plant and Soil 103:33-38.

Hendrick, D. L., and K. S. Pregitzer. 1992a. Spatial variation in tree root distribution and growth associated with minirhizotrons. Plant and Soil 143:283-288.

Hendrick, D. L., and K. S. Pregitzer. 1992b. The demography of fine roots in a northern hardwood forest. Ecology 73: 1094-1104

Jacques, W. A., and R. H. Schwass. 1956. Root development in some common New Zealand pasture plants. VII. Seasonal root replacement in perennial ryegrass (Lolium perenne), Italian ryegrass (L. multiflorum), and tall fescue (Festuca arundinacea). New Zealand Journal of Science and Technology 37:569-583.

Joslin, J. D., and G. S. Henderson. 1984. The determination of percentages of living tissue in woody fine root samples using triphenyltetrazolium chloride. Forest Science 30: 965-970.

Knievel, D. P. 1973. Procedure for estimating ratio of living to dead root dry matter in root core samples. Crop Science 13:124-126.

Murphy, J. A., M. G. Hendricks, and P. E. Rieke. 1994. Turfgrass root systems evaluated using minirhizotron and video recording methods. Agronomy Journal 86:247-250.

Parker, C. J., M. K. V. Carr, N. J. Jarvis, B. O. Puplampu, and V. H. Lee. 1991. An evaluation of the minirhizotron technique for estimating root distribution in potatoes. Journal of Agricultural Science 116:341-350.

Samson, B. K., and T. R. Sinclair. 1994. Soil core and minirhizotron comparison for the determination of root length density. Plant and Soil 161:225-232.

Steel, R. G. D., and J. H. Torrie. 1960. Principles and procedures of statistics. McGraw Hill, New York, New York USA.

Upchurch, D. R. 1985. Relationship between observations in minirhizotrons and true root length density. Dissertation. Texas Tech University, Lubbock (Dissertation Abstract 8528594).

- 1987. Conversion of minirhizotron-root intersections to root length density. Pages 51-66 in H. M. Taylor, editor. Minirhizotron observation tubes: methods and ap- 
plications for measuring rhizosphere dynamics. American Society of Agronomy, Special Publication Number 50.

Upchurch, D. R., and J. T. Ritchie. 1983. Root observations using a video recording system in mini-rhizotrons. Agronomy Journal 73:1009-1015.

Volkmar, K. M. 1993. A comparison of minirhizotron tech- niques for estimating rootlength density in soils of different bulk densities. Plant and Soil 157:239-245.

Manuscript received 16 May 1994; revised 22 January 1995; accepted 13 February 1995.
Ecology, 76(7), 1995, pp. 2334-2337

(C) 1995 by the Ecological Society of America

\section{GALL-FORMING INSECT DIVERSITY IS LINKED TO SOIL FERTILITY VIA HOST PLANT TAXON}

\section{K. Rosalind Blanche and Mark Westoby'}

Observations made by Fernandes and Price (1991) at sites in Arizona, USA, and Minas Gerais, Brazil, suggested that host plant adaptations to infertility result in higher numbers of gall-forming insect species on infertile soils than on fertile soils. Our paper reports an independent test of the relationship between galling and soil fertility in a different biogeographical province, that of New South Wales, Australia. Accumulation of such tests from many parts of the world is essential to the ultimate development of a theory on the global distribution of gall-forming insect species.

Long retention of parts is one potentially relevant adaptation of plants to infertile soils (Coley et al. 1985). Reliable, long-term sites are needed by gall insect species because most are unable to move to a new site once gall initiation has commenced. High concentrations of secondary compounds, such as oils and phenols, are also characteristic of plants growing on infertile soils (McKey et al. 1978). These are thought to benefit gall insects by protecting them from chewing herbivores, fungi, and other micro-organisms (Cornell 1983).

Insect-induced galls vary in complexity from simple, open deformations to complex, highly organized, enclosed structures. Complex galls are likely to be occupied by the gall insect for a longer period than are simple galls. The advantages afforded by long-lived plant parts and high concentrations of secondary compounds in plant tissues could be particularly important for gall-forming insect species with long-lived, complex galls. We measured the number and complexity of gall-forming insect species at low- and high-fertility

School of Biological Sciences, Macquarie University, New South Wales 2109 Australia. sites to determine whether gall species richness and complexity were correlated with soil fertility in Australia.

\section{Methods}

Eight locations in National Parks or State Forests close to Sydney, Australia $\left(\approx 34^{\circ} \mathrm{S}, 151^{\circ} \mathrm{E}\right)$ were chosen for this study. At each location a $50 \times 20 \mathrm{~m}$ site was marked out. Total soil phosphorus (in milligrams per kilogram) at each site was measured by taking five $(20 \times 20 \mathrm{~cm})$ random samples of the top $20 \mathrm{~cm}$ of soil, bulking the samples, and analyzing them by standard methods (Lambert 1983). Total soil phosphorus was used as the best single indicator of soil fertility (Bowen 1981, Williams and Raupach 1983) as it is a limiting macronutrient, is not very soluble, and atmospheric inputs are small.

The sites were visited three times between May 1991 and April 1992. During each visit 200 plants $<50 \mathrm{~cm}$ high and 100 plants $>50 \mathrm{~cm}$ high were chosen randomly and searched for insect-induced galls. All plant growth forms present were included. Samples of all insect stages obtained, their galls, and their host plant species were preserved in wet or dry reference collections, as appropriate.

Gall species were grouped into two categories according to whether they had a complex or simple form. Gall insects were keyed to species level when possible, but the taxonomy for many groups is poorly known. For this reason morphospecies (based on the external and internal morphology of the gall and the insects in it) was used in conjunction with gall species to estimate gall insect diversity. When the term "gall species" is used in subsequent parts of this paper "gall morphospecies" is implied. The number of gall morphospecies is a relatively reliable estimate of species number because gall morphology is usually distinctive for each insect species (Cornell 1985, Taper and Case 1987).

Relationships between site characteristics (soil fertility, gall species richness, proportion of complex gall species, total plant species richness, proportion of plant species galled, and myrtaceous tree species richness) were determined by Pearson correlation matrix. Path analysis (Sokal and Rohlf 1981) was used to decompose the effects of soil fertility and myrtaceous tree 